\title{
Marginal cost curves for water footprint reduction in irrigated agriculture: guiding a cost-effective reduction of crop water consumption to a permit or benchmark level
}

\author{
Abebe D. Chukalla ${ }^{1}$, Maarten S. Krol ${ }^{1}$, and Arjen Y. Hoekstra ${ }^{1,2}$ \\ ${ }^{1}$ Twente Water Centre, University of Twente, Enschede, the Netherlands \\ ${ }^{2}$ Institute of Water Policy, Lee Kuan Yew School of Public Policy, National University of Singapore, Singapore \\ Correspondence to: Abebe D. Chukalla (a.d.chukalla@utwente.nl)
}

Received: 4 February 2017 - Discussion started: 17 February 2017

Revised: 24 May 2017 - Accepted: 8 June 2017 - Published: 13 July 2017

\begin{abstract}
Reducing the water footprint (WF) of the process of growing irrigated crops is an indispensable element in water management, particularly in water-scarce areas. To achieve this, information on marginal cost curves (MCCs) that rank management packages according to their costeffectiveness to reduce the WF need to support the decision making. MCCs enable the estimation of the cost associated with a certain WF reduction target, e.g. towards a given WF permit (expressed in $\mathrm{m}^{3} \mathrm{ha}^{-1}$ per season) or to a certain WF benchmark (expressed in $\mathrm{m}^{3} \mathrm{t}^{-1}$ of crop). This paper aims to develop MCCs for WF reduction for a range of selected cases. AquaCrop, a soil-water-balance and cropgrowth model, is used to estimate the effect of different management packages on evapotranspiration and crop yield and thus the WF of crop production. A management package is defined as a specific combination of management practices: irrigation technique (furrow, sprinkler, drip or subsurface drip); irrigation strategy (full or deficit irrigation); and mulching practice (no, organic or synthetic mulching). The annual average cost for each management package is estimated as the annualized capital cost plus the annual costs of maintenance and operations (i.e. costs of water, energy and labour). Different cases are considered, including three crops (maize, tomato and potato); four types of environment (humid in UK, sub-humid in Italy, semi-arid in Spain and arid in Israel); three hydrologic years (wet, normal and dry years) and three soil types (loam, silty clay loam and sandy loam). For each crop, alternative WF reduction pathways were developed, after which the most cost-effective pathway was selected to develop the MCC for WF reduction. When aiming
\end{abstract}

at WF reduction one can best improve the irrigation strategy first, next the mulching practice and finally the irrigation technique. Moving from a full to deficit irrigation strategy is found to be a no-regret measure: it reduces the WF by reducing water consumption at negligible yield reduction while reducing the cost for irrigation water and the associated costs for energy and labour. Next, moving from no to organic mulching has a high cost-effectiveness, reducing the WF significantly at low cost. Finally, changing from sprinkler or furrow to drip or subsurface drip irrigation reduces the WF, but at a significant cost.

\section{Introduction}

In many places, water use for irrigation is a major factor contributing to water scarcity (Rosegrant et al., 2002; Mekonnen and Hoekstra, 2016), which will be worsened by increasing demands for food and biofuels (Ercin and Hoekstra, 2014). In many regions, climate change will aggravate water scarcity by affecting the spatial patterns of precipitation and evaporation (Vörösmarty et al., 2000; Fischer et al., 2007). Reducing the water footprint (WF) of crop production, i.e. the consumption of rainwater (green WF) and irrigation water (blue WF) per unit of crop, is a means of increasing water productivity and reducing water scarcity (Hoekstra, 2017). To ensure that the blue WF in a catchment remains within the maximum sustainable level given the water renewal rate in the catchment, Hoekstra (2014) proposes to establish a blue WF cap per catchment and issue no more blue WF permits to 
individual users than fit within the cap. This would urge water users to reduce their blue WF to a level that is sustainable within the catchment. Additionally, in order to increase water use efficiency, Hoekstra (2014) proposes water footprint benchmarks for specific processes and products as a reference for what is a reasonable level of water consumption per unit of production. This would provide an incentive for water users to reduce their WF per unit of product down to a certain reasonable reference level. The reduction of the WF in irrigated agriculture to the benchmark level relates to improving the physical water use efficiency or increasing water productivity (Molden et al., 2010), thus relieving water scarcity (Mekonnen and Hoekstra, 2014; Zhuo et al., 2016; Zwart et al., 2010). WF reduction in irrigated crop production can be achieved through a range of measures, including a change in mulching practice or in irrigation technique or strategy. Chukalla et al. (2015) studied the effectiveness of different combinations of irrigation technique, irrigation strategy and mulching practice in terms of WF reduction. No research thus far has been carried out regarding the costs of WF reduction. A relevant question though is how much it costs to reduce the WF of crop production to a certain target such as a WF benchmark for the water consumption per tonne of crop or a WF permit for the water consumption per area.

The current study makes a first effort in response to this question by analysing the cost-effectiveness of various measures in irrigated crop production in terms of cost per unit of WF reduction and introducing marginal cost curves (MCC) for WF reduction. An MCC for WF reduction is a tool that presents how different measures can be applied subsequently in order to achieve an increasing amount of WF reduction, whereby measures are ordered according to their costeffectiveness (WF reduction achieved per cost unit). Every new measure introduced brings an additional (i.e. marginal) cost and an incremental (marginal) reduction of the WF. There are model-driven and expert-based approaches to develop an MCC. The two approaches have been applied extensively to assess the costs of carbon footprint reduction in various studies, focusing on various sectors and regions. Enkvist et al. (2007) show cost curves for reducing greenhouse gas emissions for different regions in the world. Lewis and Gomer (2008) develop an MCC for reducing greenhouse gas emissions of all sectors in Australia, and MacLeod et al. (2010) develop an MCC for the agricultural sector in the UK. A detailed method to derive MCCs for the most economically efficient reductions in greenhouse gas emissions in the agricultural sector is presented by Bockel et al. (2012). The weaknesses and strengths intrinsic to different methods of deriving MCCs of greenhouse gas reduction are reviewed in different papers (Kesicki, 2010; Kesicki and Strachan, 2011; Kesicki and Ekins, 2012).

The application of MCCs in the water sector is just starting. Addams et al. (2009) apply MCCs for closing the gap between water supply and demand in irrigated agriculture, par- ticularly focussing on the reduction of irrigation water withdrawal. Khan et al. (2009) discuss two possible pathways to increase water productivity and energy use efficiency in food production. This work, however, does not explicitly specify the measures and their cost-effectiveness, which would inform the unit cost of improving water and energy use efficiency. Other studies, like Gonzalez-Alvarez et al. (2006) and Samarawickrema and Kulshreshtha (2009), focus on the marginal cost of water but do not develop MCCs. The first study mentioned studies how farmers would respond if the marginal cost of irrigation water is changed; the second study assesses the marginal value of irrigation water in the production of alternative crops in order to allocate the water based on the highest marginal value. In the area of WF reduction specifically, MCCs have been developed only once, not in the agricultural sector however, but in a case for some factories in different industrial sectors using the expert-based approach (Tata-Group, 2013). The current paper pioneers by developing and applying a model-driven MCC in the area of WF reduction in irrigated agriculture. It thus fills a gap of the existing literature on WF reduction, which generally lacks the practical and economic component: what are the subsequent steps and associated costs to achieve increasing levels of water footprint reduction.

The objective of this study is to develop alternative WF reduction pathways and the MCC for WF reduction in irrigated crop production. We do so for a number of crops and environments. We apply the AquaCrop model, a soil-water-balance and crop-growth model that can be used to estimate the WF of crop production under different management practices, linked with a cost model that calculates annual costs related to different management practices, to systematically assess both WF and costs of 20 management packages. Four case study areas are considered: Rothamsted in the UK, Bologna in Italy, Badajoz in Spain, and Eilat in Israel. Based on the outcomes we construct WF reduction pathways and marginal cost curves. Finally, we illustrate the application of the MCC for WF reduction with a selected case with a certain WF reduction target given a situation where the actual WF needs to be reduced given a cut in the WF permit.

\section{Method and data}

\subsection{Research set-up}

We consider the production of three crops (maize, tomato and potato) under four environments (humid, sub-humid, semiarid and arid), three hydrologic years (wet, normal and dry year) and three soil types (loam, silty clay loam and sandy loam). We distinguish 20 management packages, whereby each management package is defined as a specific combination of management practices: irrigation technique (furrow, sprinkler, drip or subsurface drip); irrigation strategy (full or 


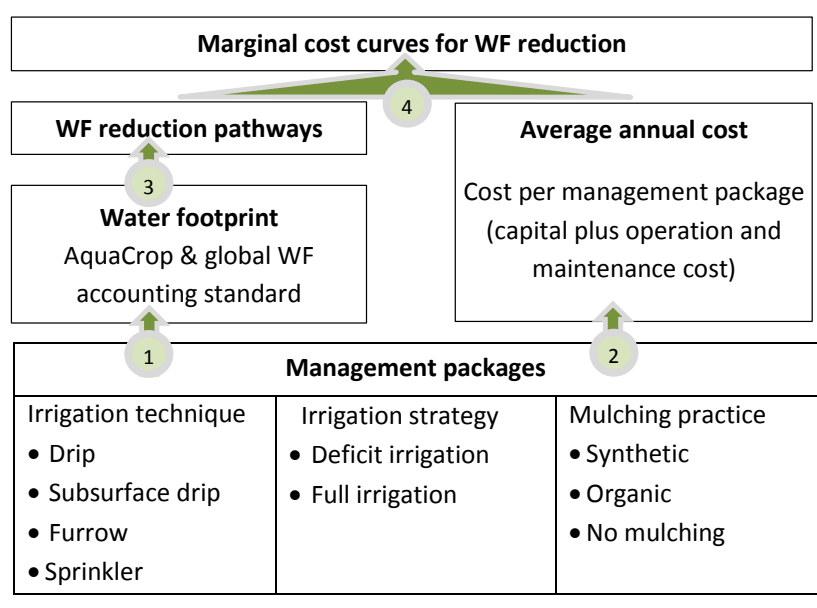

Figure 1. Flow chart for developing marginal cost curves for crop production.

deficit irrigation); and mulching practice (no, organic or synthetic mulching).

We develop the marginal cost curves (MCCs) for WF reduction in irrigated crop production in four steps (Fig. 1). First, we calculate the WF of growing a crop under the different environmental conditions and management packages using the AquaCrop model (Raes et al., 2013). Second, the total annual average costs for the management packages were calculated. Third, we constructed plausible WF reduction pathways starting from different initial situations. A WF reduction pathway shows a sequence of complementary measures, stepwise moving from an initial management package to management packages with lower WFs. Finally, MCCs for WF reduction were deduced based on reduction potential and cost-effectiveness of the individual steps. This approach does not aim to represent a cost-benefit analysis from an agroeconomic perspective. Reduced costs through water savings are included, but monetary benefits to the farmer through increased yield or product quality are not included. In this way, the approach fully focusses on costs to save water. Yield increases do have a direct impact on final results by reducing the WF per unit of product.

\subsection{Management packages}

Each management package is a combination of a specific irrigation technique, irrigation strategy and mulching practice. We consider four irrigation techniques, two irrigation strategies and three mulching practices. From the 24 possible combinations, we exclude four unlikely combinations, namely the combinations of furrow and sprinkler techniques with synthetic mulching (with either full or deficit irrigation), leaving 20 management packages considered in this study.

The four irrigation techniques differ considerably in the wetted area generated by irrigation (Ali, 2011). In the analysis, default values from the AquaCrop model are taken for the wetted area for each irrigation, as recommended by Raes et al. (2013). For furrow irrigation, an $80 \%$ wetting percentage is assumed to be representative for a narrow bed furrow, from the indicative range of 60 to $100 \%$. For the sprinkler, drip and subsurface drip irrigation techniques, wetted areas by irrigation of 100,30 and $0 \%$, respectively, are used.

Two irrigation strategies are analysed: full and deficit irrigation. Irrigation requires two principal decisions of scheduling: the volume of water to be irrigated and timing of irrigation. Full irrigation is an irrigation strategy in which the full evaporative demand is met; this strategy aims at maximizing yield. Its irrigation schedule is simulated through automatic generation of the required irrigation to avoid any water stress. The irrigation schedule in the no water stress condition is crop-dependent: the soil moisture is refilled to field capacity when 20,36 and $30 \%$ of readily available water (RAW) of the soil is depleted for maize, potato and tomato, respectively (FAO, 2012). This scheduling results in a high irrigation frequency, which is impractical in the case of furrow and sprinkler irrigation. To circumvent such unrealistic simulation for the case of furrow and sprinkler irrigation, the simulated irrigation depths are aggregated in such a way that a time gap of a week is maintained between two irrigation events.

Deficit irrigation (DI) is the application of water below the evapotranspiration requirements (Fereres and Soriano, 2007) by limiting water applications particularly during less drought-sensitive growth stages (English, 1990). The deficit strategy is established by reducing the irrigation supply below the full irrigation requirement. We extensively tested various deficit irrigation strategies that fall under two broad categories: (1) regulated deficit irrigation, where a non-uniform water deficit level is applied during the different phenological stages; and (2) sustained deficit irrigation, where the water deficit is managed to be uniform during the whole crop cycle. In the analysis of simulations, the specific deficit strategy that is optimal according to the model experiments and for yield reduction not exceeding $2 \%$ is used. AquaCrop simulates water stress responses triggered by soil moisture depletion using three thresholds for a restraint on canopy expansion, stomatal closure and senescence acceleration (Steduto et al., 2009b).

Mulching is the process of covering the soil surface around a plant to create good-natured conditions for its growth (Lamont et al., 1993; Lamont, 2005). Mulching has various purposes: reduce soil evaporation, control weed incidence and its associated water transpiration, reduce soil compaction, enhance nutrient management and incorporate additional nutrients (McCraw and Motes, 1991; Shaxson and Barber, 2003; Mulumba and Lal, 2008). The AquaCrop model simulates the effect of mulching on evaporation and represents effects of soil organic matter through soil hydraulic properties influencing the soil water balance. Soil evaporation under mulching practices is simulated by scaling the evaporation with a factor that is described by two variables (Raes et al., 2013): the fraction of soil surface covered by mulch (from 
0 to $100 \%$ ); and a parameter representing mulch material $\left(f_{\mathrm{m}}\right)$. The correction factor $(\mathrm{CF})$ for the effect of mulching on evaporation is calculated as

$\mathrm{CF}=\left(1-f_{m} \times m_{\mathrm{c}}\right)$

with $m_{\mathrm{c}}$ being the fraction of the soil covered by mulch. We assume a mulching factor $f_{\mathrm{m}}$ of 1.0 for synthetic mulching, 0.5 for organic mulching and zero for no mulching as suggested by Raes et al. (2013). Further we take a mulch cover of $100 \%$ for organic and $80 \%$ for synthetic materials, again as suggested in the AquaCrop reference manual (Raes et al., 2013).

\subsection{Calculation of water footprint per management package}

The water footprint (WF) of crop production is a volumetric measure of freshwater use for growing a crop, distinguishing between the green WF (consumption of rainwater), blue WF (consumption of irrigation water or consumption of soil moisture from capillary rise) and grey WF (water pollution) (Hoekstra et al., 2011). The green and blue WF, which are the focus in the current study, are together called the consumptive WF. To allow for a comprehensive and systematic assessment of consumptive WF, this study employs the AquaCrop model to estimate green and blue evapotranspiration (ET) and crop yield $(Y)$ to calculate blue and green WF of crop production.

We use the plug-in version of AquaCrop 4.1 (Steduto et al., 2009a; Raes et al., 2011) and determine the crop growing period based on growing degree days. The AquaCrop model simulates the soil water balance in the root zone with a daily time step over the crop growing period (Raes et al., 2012). The fluxes into and from the root zone are runoff, infiltration, evapotranspiration, drainage and capillary rise. The green and blue fractions in total ET are calculated based on the green to blue water ratio in the soil moisture, which in turn is kept track of over time by accounting for how much green and blue water enter the soil moisture, following the accounting procedure as reported in Chukalla et al. (2015).

AquaCrop simulates actual ET and biomass growth based on the type of crop grown (with specific crop parameters), the soil type, climate data such as precipitation and reference $\mathrm{ET}\left(\mathrm{ET}_{o}\right)$, and given water and field management practices. We estimate $\mathrm{ET}_{o}$ based on FAO's $\mathrm{ET}_{o}$ calculator that uses the Penman-Monteith equation (Allen et al., 1998). The model separates daily ET into crop transpiration (productive) and soil evaporation (non-productive).

Evaporation $(E)$ is calculated by multiplying the reference $\mathrm{ET}\left(\mathrm{ET}_{o}\right)$ by factors that consider the fraction of the soil surface not covered by canopy, and water stress. When the soil surface is soaked by rainfall or irrigation or when soil moisture is beyond a level called readily evaporable water (RAW), the evaporation rate is fully determined by the energy available for soil evaporation (Ritchie, 1972). When soil moisture drops below RAW, the so-called falling rate stage, the evaporation is determined by the available energy and hydraulic properties of the soil field. Experimental studies in different environments have shown that the AquaCrop model reasonably simulates evaporation, transpiration and thus ET (Afshar and Neshat, 2013; Saad et al., 2014).

The crop growth engine of AquaCrop estimates the biomass by multiplying water productivity and transpiration and computes yield by multiplying biomass by the harvest index. Water productivity is assumed to respond to atmospheric evaporative demand and atmospheric $\mathrm{CO}_{2}$ concentration (Steduto et al., 2009a).

We express the WF of crop production in two ways. The green and blue WFs per unit of land $\left(\mathrm{m}^{3} \mathrm{ha}^{-1}\right)$ are calculated as the green and blue evapotranspiration over the growing period of a crop. The green and blue WFs per unit of production $\left(\mathrm{m}^{3} \mathrm{t}^{-1}\right)$ are calculated by dividing green or blue evapotranspiration over the growing period of a crop $\left(\mathrm{m}^{3} \mathrm{ha}^{-1}\right)$ by the crop yield $\left(\mathrm{tha}^{-1}\right)$. The crop yield in terms of dry matter per hectare as obtained from the AquaCrop calculations is translated into a fresh crop yield (the marketable yield) per hectare. The dry matter fractions of marketable yield for tomato, potato and maize are estimated to be 7, 25 and $100 \%$, respectively (Steduto et al., 2012). The variability of green and blue WF is presented by calculating the standard deviation of the estimated WFs across different environments, hydrologic years and soil types.

\subsection{Estimation of annual cost per management package}

The overall cost of a management package includes initial capital or investment costs (IC), operation costs (OC), and maintenance costs (MC). Investment costs include costs of installing a new irrigation system and/or buying plastics for synthetic mulching. Operation costs refer to costs for irrigation water, energy and labour. Maintenance costs include labour and material costs. Both OC and MC are expressed as annual cost (USD ha ${ }^{-1} \mathrm{yr}^{-1}$ ).

Figure 2 shows the average annual investment cost of irrigation techniques and their lifespan. The data are derived from different sources as specified in Appendices A and B. Investment costs that were reported as one-time instalment costs were converted to equivalent annual costs based on a $5 \%$ interest rate and the lifespan of the techniques. The average annual maintenance cost per irrigation technique including costs for labour and material - is assumed to be equivalent to $2 \%$ of the annualized investment costs (Kay and Hatcho, 1992).

The average annual investment costs of $1112 \mathrm{USD} \mathrm{ha}^{-1}$ for synthetic mulching are based on the sources as specified in Appendix C. We further assume average operation and maintenance costs of $140 \mathrm{USD} \mathrm{ha}^{-1} \mathrm{yr}^{-1}$ for synthetic mulching and $200 \mathrm{USD} \mathrm{ha}^{-1} \mathrm{yr}^{-1}$ for organic mulching.

The operational cost related to the use of irrigation water is calculated from the amount of irrigation water applied 

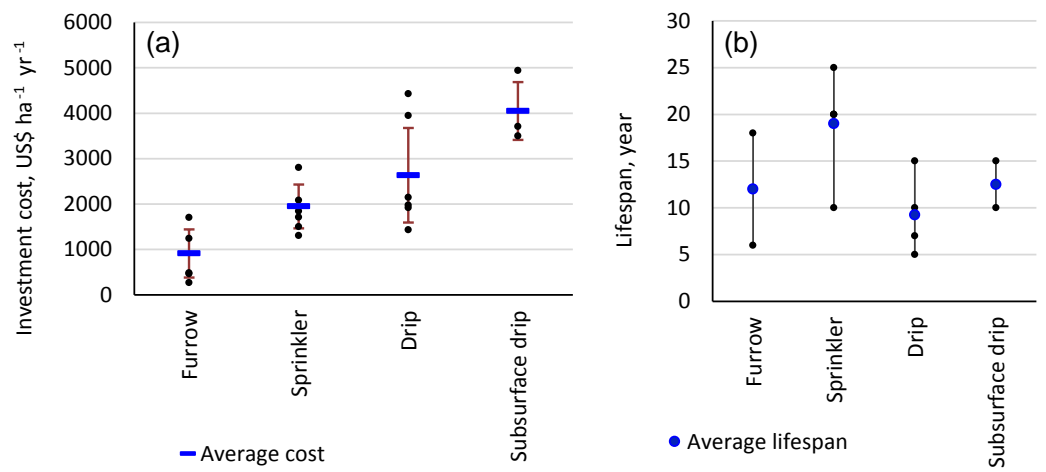

Figure 2. Annual investment cost and lifespan for irrigation techniques.

and an average unit price of water $\left(0.09 \pm 0.02 \mathrm{USD} \mathrm{m}^{-3}\right.$, Appendix E). The amount of irrigation supply is calculated by dividing the irrigation volume applied at field level simulated by AquaCrop by the application efficiency (Phocaides, 2000). Application efficiency, the ratio of actually applied to supplied irrigation water, is different per irrigation technique (Table 1). The operational cost related to energy use for sprinkler, drip and subsurface drip irrigation is calculated as the total energy demand over the growing season multiplied by the cost of energy (Appendix F). The total energy demand $(\mathrm{kWh})$ is calculated as follows (Kay and Hatcho, 1992):

seasonal energy demand $=\frac{I \times h}{367 \eta}$,

where $I$ is the volume of irrigation water to be pumped in a crop season (in $\mathrm{m}^{3}$ ), $h$ the pressure head (in $\mathrm{m}$ ) given in Table 1 and $\eta$ the pump efficiency. The pump efficiency can be between 40 and $80 \%$ for a pump running at optimum head and speed and is assumed to be $60 \%$ here (Kay and Hatcho, 1992). Energy required to transport surface water to the field or to pump up groundwater is not included in the estimates.

The operational cost related to labour is calculated as the required labour hours per irrigation event times the number of irrigation events times the cost of labour per hour. The number of irrigation events in the crop growing period is simulated with AquaCrop. The required labour hours per irrigation event are shown in Table 1 and the cost of labour per hour is given in Appendix D.

Uncertainties in the cost estimations are represented by their standard deviation. The standard deviations in the investment and maintenance costs and operational costs for water, energy and labour were systematically combined in calculating the standard deviation for the total cost estimation.

\subsection{Marginal cost curves for WF reduction}

After having calculated the total cost and WF associated with each management package, the MCC for reducing the WF per area or per unit of crop in irrigated agriculture is developed in two steps.

1. Identify alternative WF reduction pathways by arranging plausible progressive sequences of management packages from a baseline management package to a management package with the smallest WF.

2. Select the most cost-effective pathway for a certain baseline and derive from that pathway the MCC for WF reduction.

We consider two baseline management packages: the full irrigation strategy and no mulching practice combined with either furrow or sprinkler irrigation. These two management packages are the most widely deployed types of water and field management (Baldock et al., 2000).

The marginal cost (MC) of a unit WF reduction when shifting from one management package to another is calculated as

MC of a unit WF reduction

$$
=\frac{\left(\mathrm{TC}_{2}-\mathrm{TC}_{1}\right)+\left(R_{1}-R_{2}\right)}{\mathrm{WF}_{1}-\mathrm{WF}_{2}} \text {. }
$$

We consider both the additional annual cost of the new management package compared to the previous one and the reduced revenue due to crop yield reduction that may result from the new management package. In the equation, $\mathrm{TC}_{x}$ refers to the total annual cost of management package $x, R_{x}$ to the revenue from crop production when applying management package $x$, and $\mathrm{WF}_{x}$ to the water footprint of management package $x$.

The MCC shows how subsequent WF reductions can be achieved in the most cost-effective way by moving from the baseline management package to another package, and further to yet another package and so on. It shows both cost and WF reduction achieved with each step. With each step, the marginal cost of WF reduction will increase. 
Table 1. The application efficiency, labour intensity and pressure head required per irrigation technique.

\begin{tabular}{lrrr}
\hline Irrigation technique & $\begin{array}{r}\text { Application efficiency } \\
(\%)\end{array}$ & $\begin{array}{r}\text { Labour intensity } \\
\left(\mathrm{h} \mathrm{ha}^{-1} \text { per irrigation event }\right)\end{array}$ & $\begin{array}{r}\text { Pressure head } \\
(\mathrm{m})\end{array}$ \\
\hline Source & $\begin{array}{r}\text { Brouwer et al. (1989), } \\
\text { Kay and Hatcho (1992), } \\
\text { Phocaides (2000) }\end{array}$ & Kay and Hatcho (1992) & $\begin{array}{r}\text { Reich et al. (2009) and } \\
\text { Phocaides (2000) }\end{array}$ \\
\hline Furrow & 60 & $2.0-4.0$ & 0 \\
Sprinkler & 75 & $1.5-3.0$ & 25 \\
Drip & 90 & $0.2-0.5$ & 13.6 \\
Subsurface drip & 90 & $0.2-0.6$ & 13.6 \\
\hline
\end{tabular}

\subsection{Data}

The WFs were calculated for four locations (UK, Italy, Spain and Israel), three hydrological years (wet, normal and dry years) and three soil types (loam, silty clay loam, and sandy loam). The input data on climate and soil were collected from four sites: Rothamsted in the UK $\left(52.26^{\circ} \mathrm{N}, 0.64^{\circ} \mathrm{E}\right.$; $69 \mathrm{~m}$ above mean sea level), Bologna in Italy $\left(44.57^{\circ} \mathrm{N}, 11.53^{\circ} \mathrm{E} ; 19 \mathrm{~m}\right.$ a.m.s.l. $)$, Badajoz in Spain $\left(38.88^{\circ} \mathrm{N},-6.83^{\circ} \mathrm{E} ; 185 \mathrm{ma}\right.$ a.m.s.l.) and Eilat in Israel $\left(29.33^{\circ} \mathrm{N}, 34.57^{\circ} \mathrm{E} ; 12 \mathrm{~m}\right.$ a.m.s.l.). These sites are characterized by humid, sub-humid, semi-arid, and arid environments, respectively. Daily observed climatic data (rainfall, minimum and maximum temperature) were extracted from the European Climate Assessment and Dataset (ECAD) (Klein Tank et al., 2002). Wet, normal and dry years were selected from 20 years of daily rainfall data (observed data from the period 1993 to 2012). Daily $\mathrm{ET}_{o}$ values for the wet, normal and dry years were derived using FAO's ET ET $_{o}$ calculator (Raes, 2012). Soil texture data, which are extracted with a resolution of $1 \times 1 \mathrm{~km}^{2}$ from the European Soil Database (Hannam et al., 2009), are used to identify the soil type based on the soil texture triangle calculator (Saxton et al., 1986). The physical characteristics of the soils are taken from the default parameters in AquaCrop. For crop parameters, by and large we take the default values as represented in AquaCrop. However, the rooting depth for maize at the Bologna site is restricted to a maximum of $0.7 \mathrm{~m}$ to account for the actual local condition of a shallow groundwater table (average $1.5 \mathrm{~m}$ ). The main components of the average annual cost per management package have been collected from the literature. We use crop prices per crop and per country averaged over 5 years (20102015) from FAOSTAT (2017); the costs for water, labour and energy are averaged over data for Spain, Italy and the UK, i.e. from three of the four countries studied here. An overview of the costs and their sources is presented in Appendices A to F. In presenting the WF estimates per management package, we show averages over the different cases as well as the range of outcomes for the cases (different environments, hydrologic years and soil types). To develop the MCCs, we use the averages.

\section{Results}

\subsection{Water footprint and cost per management package}

Figures 3 and 4 show the WF per area and WF per unit of crop, and the annual average costs corresponding to 20 management packages.

For each combination of a certain mulching practice and irrigation strategy, the consumptive WF and the blue WF in particular decrease when we move from sprinkler to furrow to drip and further to subsurface drip irrigation. Under a given irrigation strategy and mulching practice, the WF in $\mathrm{m}^{3} \mathrm{ha}^{-1}$ in the case of subsurface drip irrigation is 6.2$13.3 \%$ smaller than in the case of sprinkler irrigation. The annual average cost always increases from furrow to sprinkler and further to drip and subsurface drip irrigation. Under a given mulching practice and irrigation strategy, the cost in the case of furrow irrigation is 58-63\% smaller than in the case of subsurface drip irrigation. The cost of furrow irrigation is small particularly because of the relatively low investment cost, which is higher for sprinkler and even higher for drip and subsurface drip irrigation. The operational costs, by contrast, are higher for sprinkler and furrow than for drip or subsurface drip irrigation, because of the higher water consumption and thus cost for sprinkler and furrow. Sprinkler has the highest operational cost because it requires a high pressure head to distribute the water (hence the higher energy cost).

Under a given irrigation technique and mulching practice, DI always results in a slightly smaller WF in $\mathrm{m}^{3} \mathrm{ha}^{-1}$ (in the range of 1.6-5.7\%) and lower cost (in the range of 4$14 \%$ ) as compared to full irrigation (FI). The decrease in cost is due to the decrease in water and pumping energy. The WF of crop production always decreases in a stepwise way when going from no mulching to organic mulching and then to synthetic mulching, while the costs increase along the move. This cost increase relates to the growing material and labour costs when applying mulching (most with synthetic mulching), but the net cost increase is tempered by the fact that less water and pumping energy will be required. 


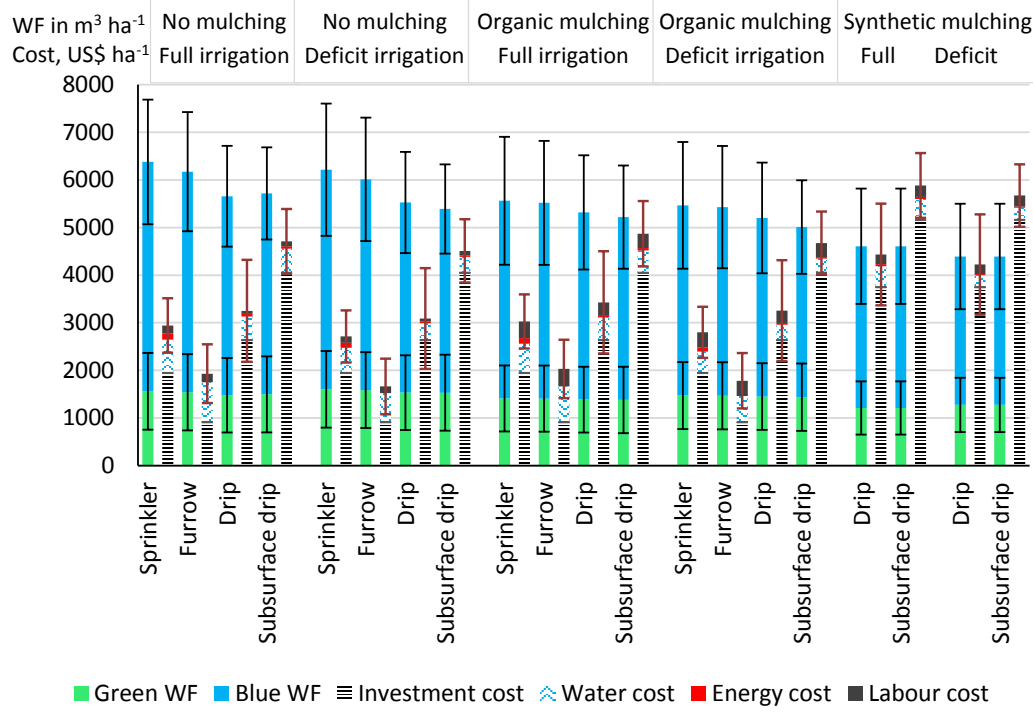

Figure 3. Average WF per area $\left(\mathrm{m}^{3} \mathrm{ha}^{-1}\right)$ for maize production and average annual costs associated with 20 management packages. The whiskers around WF estimates indicate the range of outcomes for the different cases (different environments, hydrologic years and soil types). The whiskers around cost estimates indicate uncertainties in the costs. WF estimates are split up into blue and green components; costs are split up into investment, water, energy and labour costs.

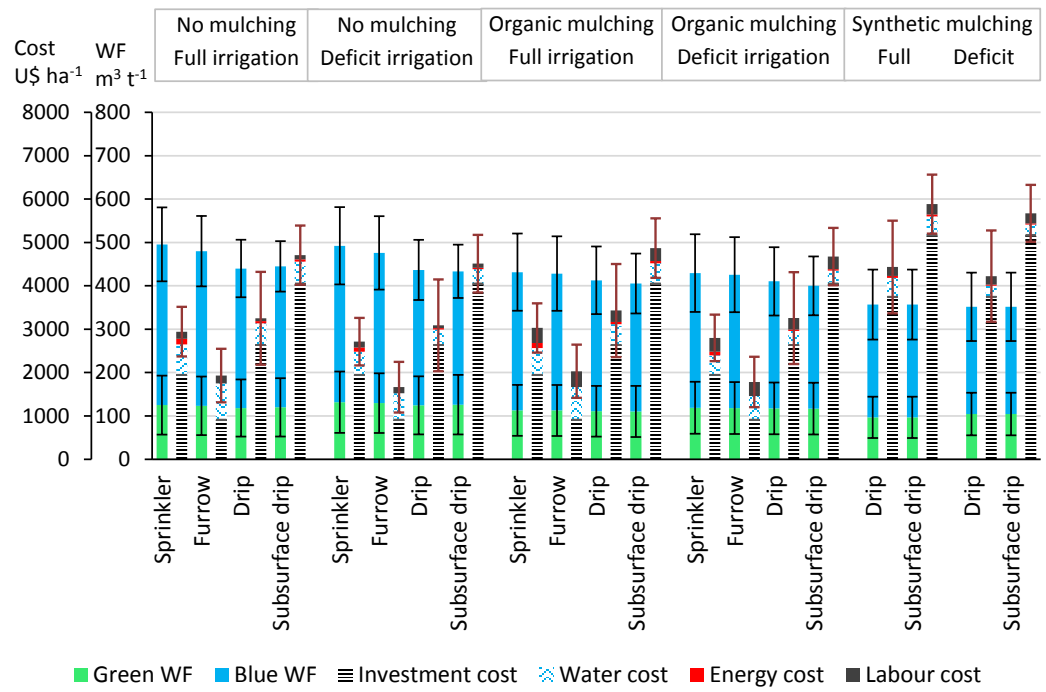

Figure 4. Average WF per product unit $\left(\mathrm{m}^{3} \mathrm{t}^{-1}\right)$ for maize production and average annual costs associated with 20 management packages. The whiskers around the WF estimates indicate the range of outcomes for the different cases (different environments, hydrologic years and soil types). The whiskers around cost estimates indicate uncertainties in the costs.

Figure 5 shows the scatter plot of the 20 management packages, the abscissa and ordinate of each point representing the average annual cost and average WF, respectively, of a particular management package. In this graph, the blue arrow indicates the direction of decreasing WF and costs. The points or management packages connected by the blue line are jointly called the Pareto optimal front or non-dominated Pareto optimal solutions. Moving from one to another management package on the line means that WF will decrease while cost increases, or vice versa, which implies that along this line there will always be a trade-off between the two variables. "Best solutions" may be identified using the MCC when policy goals are specified, for instance a certain WF re-

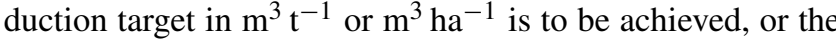
largest WF reduction is to be achieved with a given limited budget. Each management package that is not on the line can be improved in terms of reducing cost or reducing WF at no 
cost for the other variable, or even WF reduction and cost decrease can be achieved simultaneously.

\subsection{Water footprint reduction pathways}

In developing a new irrigation scheme or renovating an existing one in a water-scarce area, it would be rational to implement one of the management packages from the Pareto optimal set if the goal is to arrive at a cost-effective minimization of the WF of crop production. In an existing farm, where the management package is not in the Pareto optimal set, there can be alternative pathways towards reducing the WF. This involves a stepwise adoption of complementary measures that eventually leads to a management package in the Pareto optimal set.

Figure 6 shows alternative WF reduction pathways from the two most common baseline management packages: full irrigation and no mulching with either furrow or sprinkler irrigation. The figure shows four WF reduction pathways from the baseline with furrow irrigation and two pathways from the baseline with sprinkler irrigation. In all pathways, the WF of crop production is continually reduced by changing one thing at a time, i.e. either the irrigation technique, the irrigation strategy or the mulching practice. In some cases, a step may be accompanied by a cost reduction, but in the end most steps imply a cost increase. Logically, all pathways end at a point at the Pareto optimal front.

\subsection{Marginal cost curves for WF reduction}

Not all alternative WF reduction pathways from a specific baseline are equally cost-effective. In both cases it makes much sense to move from full to deficit irrigation first, because that reduces the WF and cost at the same time. Next, it is best to move from no to organic mulching because the cost-effectiveness of this measure is very high, which can be measured in the graph (Fig. 6) as the steep slope (high WF reduction per dollar). Finally, the most cost-effective measure, in both cases, is to move towards drip irrigation in combination with synthetic mulching. One could also move to drip irrigation and stay with organic mulching, which is also Pareto optimal; the cost of this will be less, but the WF reduction will be less as well. However, moving to drip irrigation in combination with synthetic mulching is more cost-effective (higher WF reduction per dollar) than moving to drip irrigation while staying with organic mulching.

For both baseline management packages, we have drawn the MCCs in Figs. 7 and 8 for the case of maize. The curves are shown both for reducing the WF per area (Figs. 7a and $8 \mathrm{a}$ ) and the WF per unit of product (Figs. $7 \mathrm{~b}$ and $8 \mathrm{~b}$ ). From these curves, we can read the most cost-effective measures that can subsequently be implemented. For each step we can read in the graph what the associated marginal cost is and what the associated WF reduction is. In both cases, the first step goes at a negative cost, i.e. a benefit, while the next steps go at increasing marginal cost. Each step is shown in the form of a bar, with the height and width representing the cost per unit WF reduction and the WF reduction, respectively. The area under a bar represents the total cost of implementing the measure.

For tomato and potato we find similar results as for maize, as shown by the data presented in Appendix G.

\subsection{Application of the marginal cost curve}

In this section, we elaborate a practical application of an MCC for WF reduction, using a selected case with a certain WF reduction target given a situation where the actual WF needs to be reduced given a cut in the WF permit. The future introduction of WF permits to water users or WF benchmarks for products in water-scarce areas is likely if the sustainable development goals (SGDs) are to be met, particularly SDG 6.4, which reads "by 2030, substantially increase wateruse efficiency across all sectors and ensure sustainable withdrawals and supply of freshwater to address water scarcity, and substantially reduce the number of people suffering from water scarcity". Here we will illustrate how an MCC for WF reduction can help in achieving a certain WF reduction goal.

An MCC for WF reduction - ranking measures according to their cost-effectiveness in reducing WF - can be used to estimate what measures can best be taken and what is the associated total cost to achieve a certain WF reduction target. For farmers, it will not be attractive to go beyond the implementation of those WF reduction measures that reduce costs as well, but from a catchment perspective further WF reduction may be required. An MCC will show the societal cost associated with a certain WF reduction goal. Governments, food companies and investors can make use of this information to develop incentive schemes for farmers and/or investment plans to implement the most cost-effective measures in order to achieve a certain WF reduction in a catchment or at a given farm.

In a hypothetical example, the WF in the river basin exceeds the maximum sustainable level. Agriculture in the basin consists of irrigated maize production with a current consumptive WF on the farms of $6380 \mathrm{~m}^{3} \mathrm{ha}^{-1}$. The farms apply sprinkler and full irrigation and no mulching. In order to reduce water consumption in the basin to a sustainable level, the river basin authority proposes various measures including a regulation that prohibits land expansion for crop production and the introduction of a WF permit to the maize farmers that allows them to use no more than $5200 \mathrm{~m}^{3} \mathrm{ha}^{-1}$. This means they have to reduce the WF of maize production by $1180 \mathrm{~m}^{3} \mathrm{ha}^{-1}$. Figure 9 shows how the MCC for WF reduction can help in this hypothetical example to identify what measures can best be taken to reduce the WF by the required amount and what costs will be involved.

As shown in the figure, we best implement deficit irrigation first (providing a total benefit of $189 \mathrm{USD} \mathrm{ha}^{-1}$, which is the net result of a USD 231 gain from saved water and 


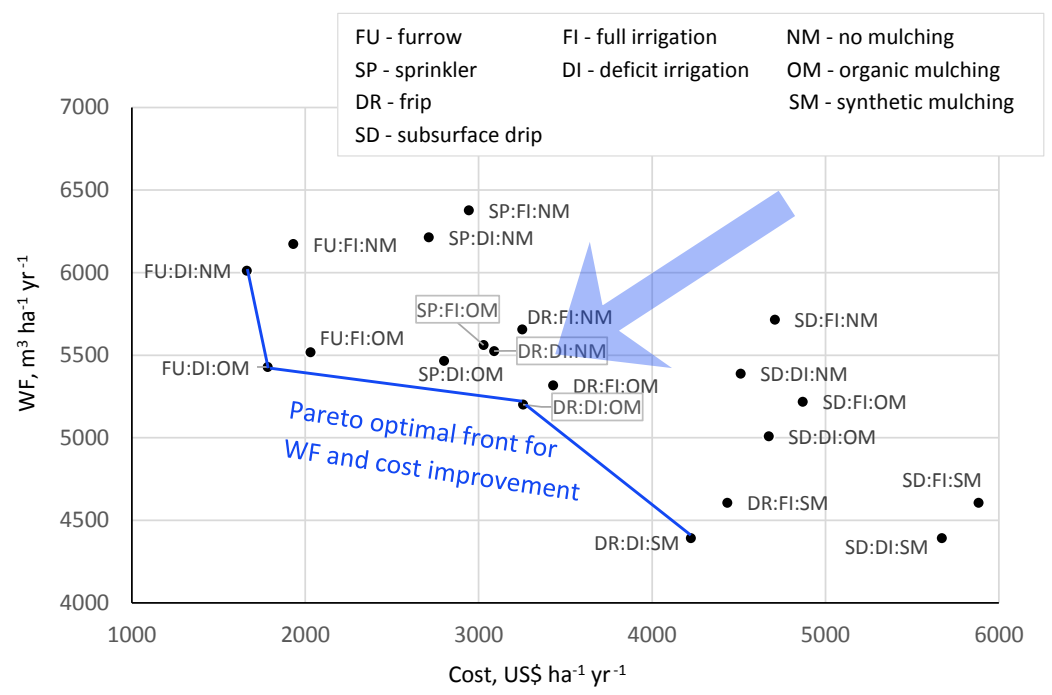

Figure 5. Pareto optimal front for WF and cost reduction in irrigated crop production. The dots represent the annual cost of maize production and the WF per area for 20 management packages. The line connects the Pareto optimal management packages.

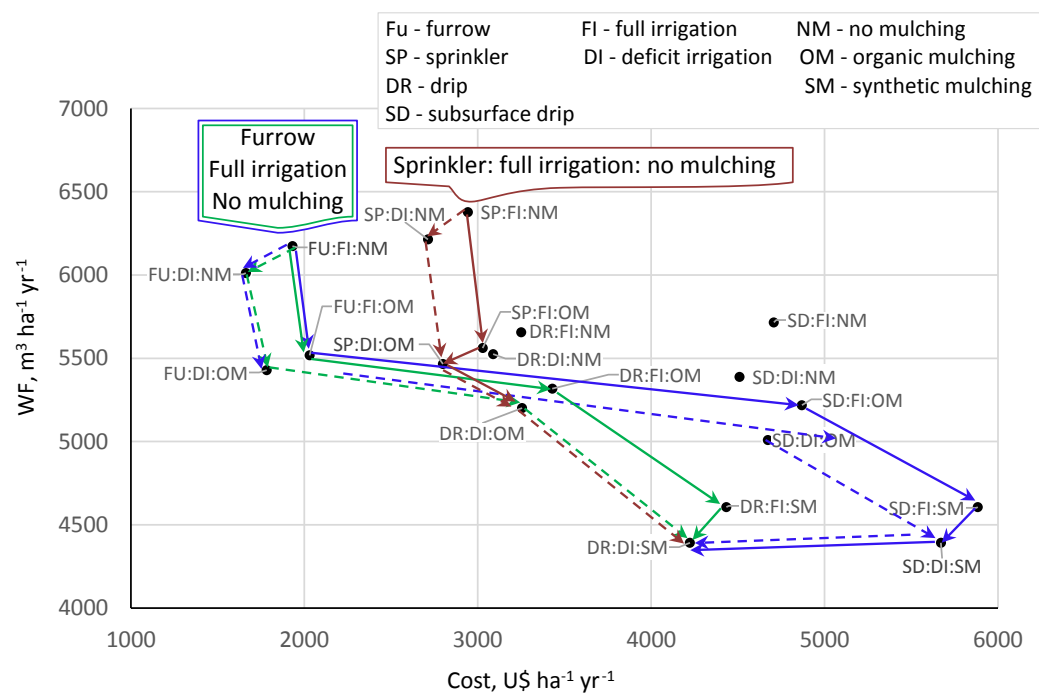

Figure 6. WF reduction pathways for maize from two baseline management packages: full irrigation and no mulching with either furrow or sprinkler irrigation.

a USD 42 loss from crop yield decline), followed by organic mulching (with a total cost of $72 \mathrm{USDha}^{-1}$ ). The third and last step to finally achieve the required WF reduction can be to implement drip irrigation combined with synthetic mulching on $25 \%$ of the maize fields (at a total cost of $366 \mathrm{USD} \mathrm{ha}^{-1}$ ). The other $75 \%$ is then still with sprinkler and organic mulching, but the combined result meets the target. Alternatively, because in this particular case the cost-effectiveness of moving to drip irrigation with organic mulching is close to the cost-effectiveness of moving to drip irrigation with synthetic mulching, one could move in the third step in $100 \%$ of the fields to drip irrigation with organic mulching, which would result in a WF reduction of
$1176 \mathrm{~m}^{3} \mathrm{ha}^{-1}$. In order to meet the full target, a small percentage of the total fields would need to implement synthetic mulching in addition.

\section{Discussion}

The current paper introduces the method for developing MCCs for WF reduction in irrigated agriculture, and shows how the MCCs can be applied to achieve a certain WF reduction target, like reducing the WF to a certain WF permit level (in $\mathrm{m}^{3} \mathrm{ha}^{-1}$ ) or WF benchmark level (in $\mathrm{m}^{3} \mathrm{t}^{-1}$ ). Water availability per catchment is limited to runoff minus envi- 

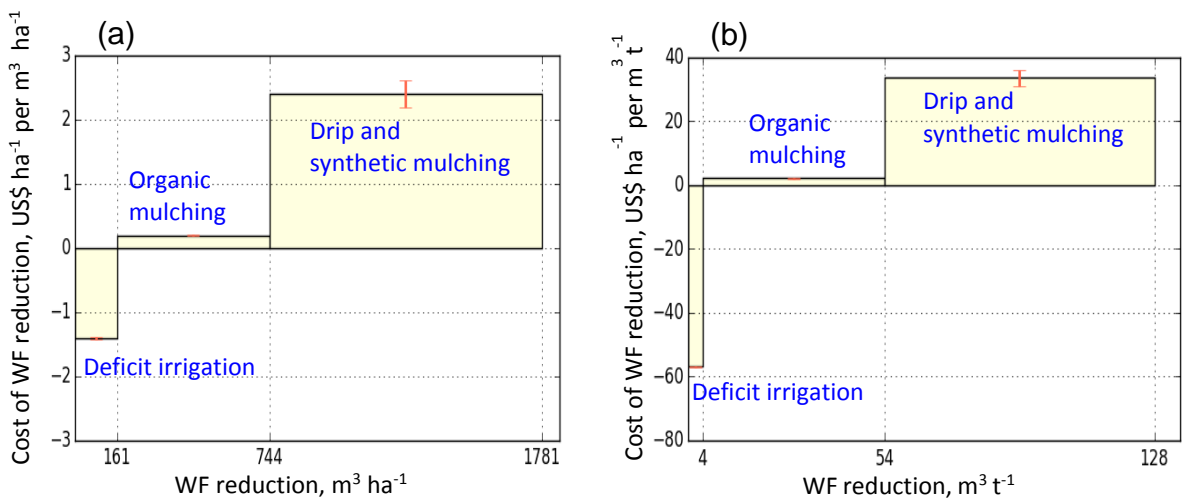

Figure 7. Marginal cost curves for WF reduction for maize for the baseline of furrow irrigation combined with full irrigation and no mulching. (a) WF reduction per area. (b) WF reduction per unit of product.
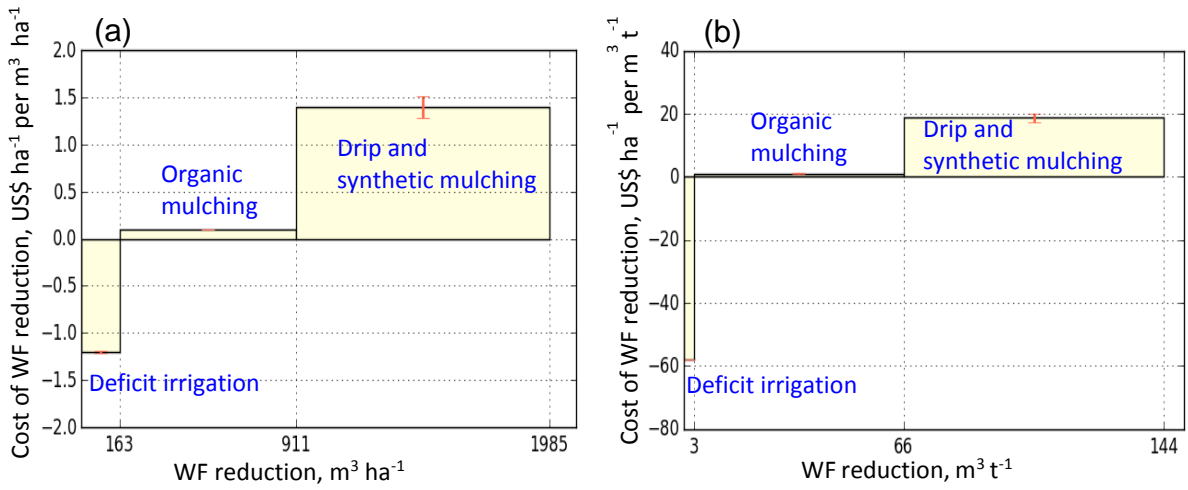

Figure 8. Marginal cost curve for WF reduction of maize for the baseline of sprinkler irrigation combined with full irrigation and no mulching. (a) WF reduction per area. (b) WF reduction per unit of product.

ronmental flow requirement (Hoekstra, 2014). When dividing the maximum amount of water available in a catchment over the croplands that need irrigation, one finds a maximum volume of water available per hectare of cropland. This could be translated in water allocation policy into a maximum WF permit per hectare; this is just one way of promoting WF reduction in areas where that is needed. Another way is to create incentives to reduce the WF per unit of production to a certain benchmark level. Thus, the MCCs we develop can be used for analysing a cost-effective WF reduction pathway given either a target level for WF per hectare or a target level for WF per unit of crop.

By comparing the cost-effectiveness of measures in reducing the WF of growing crops, we found that one can best improve first the irrigation strategy (moving from full to deficit irrigation), next the mulching practice (moving from no to organic mulching) and finally the irrigation technique (from furrow or sprinkler irrigation to drip or subsurface drip irrigation). In our cost-effectiveness analysis, we did not include the cost of bringing irrigation water from source to field. The cost will be high when the source is a deep water well and/or far away, and low if irrigation water flows to a field by gravitational force or by natural pressure, for example from an artesian aquifer or an elevated reservoir. Given a certain source and distance, the total cost to bring irrigation water from source to field will depend on the volume of water to be transported, which varies across the management packages. We excluded this cost, because it does not affect the finding from the study, as we will explain. The cost of supplying water will be highest for furrow irrigation (because this technique involves the largest irrigation water supply at field level), followed by sprinkler and drip or subsurface drip irrigation. Furthermore, the water supply cost is higher for full than for deficit irrigation. Finally, the water supply cost is highest in the case of the no-mulching practice (which requires the highest irrigation water supply, because ET is highest), followed by organic and synthetic mulching. The water supply cost for transporting the water to the field thus decreases in the direction of decreasing WF, which implies that the order of changing management practices in order to reduce WFs in the most cost-effective way does not change by including water supply costs in the equation. It implies, though, that we underestimated the cost savings associated with water supply to the field when reducing WFs. 

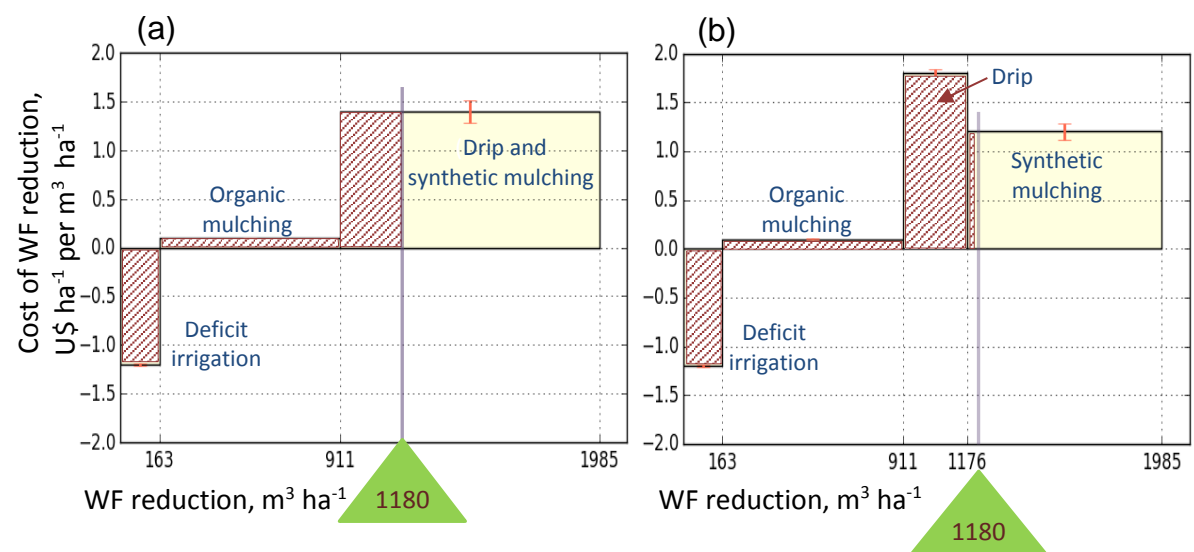

Figure 9. Application of the MCC in an example where the WF of maize production needs to be reduced. The baseline is sprinkler, full irrigation and no mulching with a WF of $6380 \mathrm{~m}^{3} \mathrm{ha}^{-1}$. This needs to be reduced by $1180 \mathrm{~m}^{3} \mathrm{ha}^{-1}$ in order to meet a given local WF permit. (a) In the third step, drip irrigation combined with synthetic mulching is implemented on $25 \%$ of the area. (b) In the third step, drip irrigation (maintaining organic mulching) is implemented on $100 \%$ of the area, while in a fourth step synthetic mulching is implemented on $0.5 \%$ of the area.

The derivation of plausible WF reduction pathways requires insight into the agronomic plausibility of successive implementation measures in the field. Our findings suggest first moving from full to deficit irrigation, then from no to organic mulching, and finally from furrow or sprinkler irrigation to drip or subsurface drip irrigation, which is a plausible pathway of changing management practices. Strictly speaking, it would also be cost-effective to first move from sprinkler to furrow and later on to drip irrigation, but in practice that is obviously not plausible given the fact that investment costs need to be spread over the lifespan of a technique. It is more plausible to change the irrigation technique only once.

One should be cautious in applying the reported specific values for costs and WF values in other areas than the ones studied here. The results may even change for the areas studied when prices change. In addition, we did not use field data for validating the simulated results. This puts a disclaimer on the simulated results, but we believe that the methods for developing MCCs for WF reduction pathways for irrigated agriculture, and the hypothetical example of this study, provide a useful reference for similar future studies. The MCCs can be of interest to farmers who are seeking to or are incentivized to reduce the WF of their production. They can also be of interest to companies in the food and beverage sector, since there is increasing interest in this sector to formulate water use efficiency targets for their supply chain and to stimulate farmers to reduce their WF. For investors, the MCCs help to explore the investment costs associated with certain WF reduction targets. Finally, the MCCs can be of interest to water managers responsible for water allocation to farmers, providing them with information on the costs to farmers if they reduce WF permits to farmers.

\section{Conclusion}

In this study, we have developed a method to obtain marginal cost curves for WF reduction in crop production. The method is innovative by employing a model that combines soil water balance accounting and a crop growth model and assessing costs and WF reduction for all combinations of irrigation techniques, irrigation strategies and mulching practices. This is a model-based approach to constructing MCCs, which has the advantage over an expert-based approach by considering the combined effects of different measures and thus accounting for non-linearity in the system (i.e. the effect of two measures combined does not necessarily equal the sum of the effects of the separate measures). While this approach has been used in the field of constructing MCCs for carbon footprint reduction (Kesicki, 2010), this has never been done before for the case of water footprint reduction.

Developing the MCC for WF reduction for three specific irrigated crops, we found that when aiming at WF reduction one can best improve the irrigation strategy first, next the mulching practice and finally the irrigation technique. Moving from a full to deficit irrigation strategy is found to be a no-regret measure: it reduces the WF by reducing water consumption at negligible yield reduction, while reducing the cost for irrigation water and the associated costs for energy and labour. Next, moving from no to organic mulching has a high cost-effectiveness, reducing the WF significantly at low cost. Finally, changing from sprinkler or furrow to drip or subsurface drip irrigation reduces the WF, but at a significant cost. 
Data availability. The daily observed rainfall and temperature data are freely available and can be downloaded from the European Climate Assessment and Dataset at http://www.ecad.eu/dailydata/. The soil data are freely available as well: they can be downloaded with $1 \mathrm{~km}$ by $1 \mathrm{~km}$ resolution at http://esdac.jrc.ec.europa.eu/ content/european-soil-database-v20-vector-and-attribute-data.

Aquacrop, the water-driven dynamic crop model that is parameterized for herbaceous crops at diverse locations in different environments, can be freely obtained from http://www.fao.org/land-water/databases-and-software/aquacrop/ software-download/en/?news_files=1. 


\section{Appendix A}

Table A1. Estimates of the investment cost of irrigation techniques (USD ha ${ }^{-1} \mathrm{yr}^{-1}$ ).

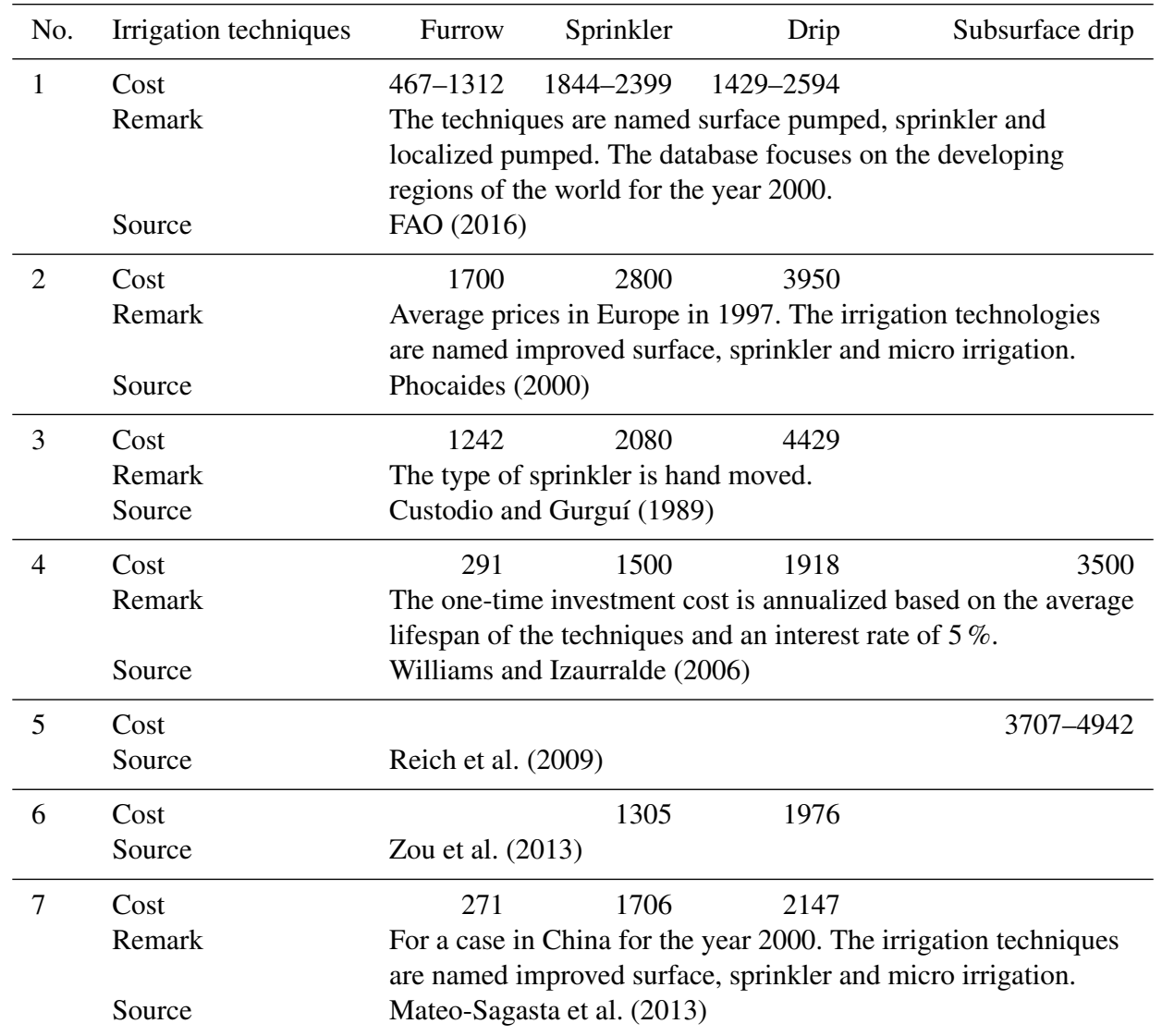

\section{Appendix B}

Table B1. Estimates of the lifespan of irrigation techniques from various sources.

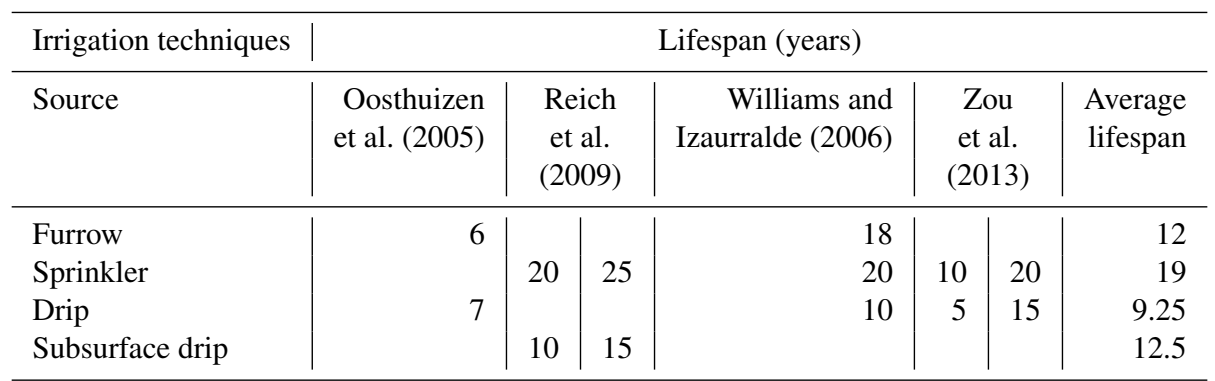




\section{Appendix C}

Table C1. Estimates for the cost of mulching (USD ha ${ }^{-1} \mathrm{yr}^{-1}$ ).

\begin{tabular}{lrrl}
\hline Mulching & $\begin{array}{r}\text { Average annual } \\
\text { investment cost }\end{array}$ & $\begin{array}{r}\text { Operation and } \\
\text { maintenance cost }\end{array}$ & Sources \\
\hline Plastic mulching & 1227 & & Lamont et al. (1993) \\
& 875 to 1750 & & Shrefler and Brandenberger (2014) \\
& 585 & 140 & Jensen and Malter (1995) \\
Average cost for plastic mulching cost \pm SD & $1112 \pm 434$ & 140 & \\
Average cost for organic mulching & & $200 \pm 100$ & Klonsky (2012) \\
\hline
\end{tabular}

\section{Appendix D}

Table D1. Labour cost per hour, in European agriculture for selected countries.

\begin{tabular}{lrl}
\hline Country & Labour cost & Source \\
\hline Italy $\left(\mathrm{EUR} \mathrm{h}^{-1}\right)$ & 6.87 & Agri-Info.Eu (2016) \\
Spain $\left(E U R ~ h^{-1}\right)$ & 4 & \\
UK $\left(\mathrm{EUR} \mathrm{h}^{-1}\right)$ & 8.6 & \\
Average $\left(\mathrm{EUR} \mathrm{h}^{-1}\right)$ & 6.5 & \\
Average \pm SD $\left(\mathrm{USD} \mathrm{h}^{-1}\right)$ & $7.2 \pm 2.3$ & \\
\hline
\end{tabular}

\section{Appendix E}

Table E1. Cost of water.

\begin{tabular}{|c|c|c|}
\hline Country & Water price & Source \\
\hline UK $\left(\mathrm{EUR} \mathrm{m}^{-3}\right)$ & 0.06 & Lallana and Marcuello (2016) \\
\hline Spain $\left(E_{U R} \mathrm{~m}^{-3}\right)$ & 0.07 & Gómez-Limón and Riesgo (2004) \\
\hline Italy $\left(\right.$ EUR m $\left.^{-3}\right)$ & 0.1 & Garrido and Calatrava (2010) \\
\hline Average (EUR m $\left.{ }^{-3}\right)$ & 0.08 & \\
\hline Average $\pm \mathrm{SD}\left(\mathrm{USD} \mathrm{m}^{-3}\right)$ & $0.09 \pm 0.02$ & \\
\hline
\end{tabular}




\section{Appendix F}

Table F1. Cost of energy, Eurostat (2016).

\begin{tabular}{lrrrr}
\hline & \multicolumn{3}{c}{ Year } & \\
\cline { 2 - 3 } Country & 2012 & 2013 & 2014 & Average \\
\hline Italy & 0.178 & 0.172 & 0.174 & 0.17 \\
Spain & 0.12 & 0.12 & 0.117 & 0.12 \\
UK & 0.119 & 0.12 & 0.134 & 0.12 \\
Average (EUR kWh & & 0.14 \\
Average \pm SD $\left(\mathrm{USD} \mathrm{kWh}^{-1}\right.$ ) & & $0.15 \pm 0.03$ \\
\hline
\end{tabular}

Appendix G: Summary of marginal cost and WF reduction per subsequent measure in the marginal cost curves for WF reduction in maize, tomato and potato production

Table G1. Marginal cost and WF reduction per subsequent measure in the MCC for WF reduction in maize production for the baseline of furrow irrigation combined with full irrigation and no mulching.

\begin{tabular}{lrr|rrr}
\hline \multirow{2}{*}{ Measures } & \multicolumn{2}{c|}{ Marginal cost } & \multicolumn{2}{c}{ WF reduction } & \multicolumn{2}{c}{ Total cost USD ha $^{-1}$} \\
\cline { 2 - 5 } & USD ha $^{-1}$ per m $^{3} \mathrm{ha}^{-1}$ & USD ha $^{-1} \mathrm{per} \mathrm{m}^{3} \mathrm{t}^{-1}$ & $\mathrm{~m}^{3} \mathrm{ha}^{-1}$ & $\mathrm{~m}^{3} \mathrm{t}^{-1}$ & \\
\hline Deficit irrigation & -1.7 & -66.7 & 161 & 4 & -269 \\
Organic mulching & 0.2 & 2.4 & 583 & 50 & 120 \\
Drip and synthetic mulching & 2.4 & 32.9 & 1037 & 74 & 2441 \\
\hline
\end{tabular}

Table G2. Marginal cost and WF reduction per subsequent measure in the MCC for WF reduction in maize production for the baseline of sprinkler irrigation combined with full irrigation and no mulching.

\begin{tabular}{lrr|rrr}
\hline \multirow{2}{*}{ Measures } & \multicolumn{2}{c|}{ Marginal cost } & \multicolumn{2}{c}{ WF reduction } & \multirow{2}{*}{ Total cost USD ha $^{-1}$} \\
\cline { 2 - 5 } & USD ha $^{-1}$ per m $^{3}$ ha $^{-1}$ & USD ha $^{-1}$ per m $^{3} \mathrm{t}^{-1}$ & $\mathrm{~m}^{3} \mathrm{ha}^{-1}$ & $\mathrm{~m}^{3} \mathrm{t}^{-1}$ & \\
\hline Deficit irrigation & -1.4 & -70.9 & 163 & 3 & -231 \\
Organic mulching & 0.1 & 1.4 & 748 & 63 & 87 \\
Drip and synthetic mulching & 1.3 & 18.3 & 1073 & 78 & 1424 \\
\hline
\end{tabular}

Table G3. Marginal cost and WF reduction per subsequent measure in the MCC for WF reduction in tomato production for the baseline of furrow irrigation combined with full irrigation and no mulching.

\begin{tabular}{lrr|rrr}
\hline \multirow{2}{*}{ Measures } & \multicolumn{2}{c|}{ Marginal cost } & \multicolumn{2}{c}{ WF reduction } & \multirow{2}{*}{ Total cost USD ha $^{-1}$} \\
\cline { 2 - 5 } & USD ha $^{-1}$ per m $^{3} \mathrm{ha}^{-1}$ & USD ha $^{-1} \mathrm{per} \mathrm{m}^{3} \mathrm{t}^{-1}$ & $\mathrm{~m}^{3} \mathrm{ha}^{-1}$ & $\mathrm{~m}^{3} \mathrm{t}^{-1}$ & \\
\hline Deficit irrigation & -0.4 & -256.1 & 752 & 1 & -331 \\
Organic mulching & 0.2 & 16.0 & 750 & 8 & 122 \\
Drip and synthetic mulching & 2.3 & 270.2 & 1094 & 9 & 2487 \\
\hline
\end{tabular}


Table G4. Marginal cost and WF reduction per subsequent measure in the MCC for WF reduction in tomato production for the baseline of sprinkler irrigation combined with full irrigation and no mulching.

\begin{tabular}{lrr|rrr}
\hline \multirow{2}{*}{ Measures } & \multicolumn{2}{c|}{ Marginal cost } & \multicolumn{2}{c}{ WF reduction } & \multirow{2}{*}{ Total cost USD ha $^{-1}$} \\
\cline { 2 - 4 } & $\mathrm{USD} \mathrm{ha}^{-1} \mathrm{per} \mathrm{m}^{3} \mathrm{ha}^{-1}$ & $\mathrm{USD} \mathrm{ha}^{-1} \mathrm{per} \mathrm{m}^{3} \mathrm{t}^{-1}$ & $\mathrm{~m}^{3} \mathrm{ha}^{-1}$ & $\mathrm{~m}^{3} \mathrm{t}^{-1}$ & \\
\hline Deficit irrigation & -0.4 & -275.5 & 840 & 1 & -323 \\
Organic mulching & 0.1 & 7.4 & 1045 & 10 & 73 \\
Drip irrigation & 1.4 & 143.2 & 1086 & 4 & 502 \\
Synthetic mulching & & 153.7 & & 6 & 983 \\
\hline
\end{tabular}

Table G5. Marginal cost and WF reduction per subsequent measure in the MCC for WF reduction in potato production for the baseline of furrow irrigation combined with full irrigation and no mulching.

\begin{tabular}{lrr|rrr}
\hline \multirow{2}{*}{ Measures } & \multicolumn{2}{c|}{ Marginal cost } & \multicolumn{2}{c}{ WF reduction } & \multicolumn{2}{c}{ Total cost USD ha $^{-1}$} \\
\cline { 2 - 5 } & USD ha $^{-1}$ per m $^{3} \mathrm{ha}^{-1}$ & $\mathrm{USD} \mathrm{ha}^{-1} \mathrm{per} \mathrm{m}^{3} \mathrm{t}^{-1}$ & $\mathrm{~m}^{3} \mathrm{ha}^{-1}$ & $\mathrm{~m}^{3} \mathrm{t}^{-1}$ & \\
\hline Deficit irrigation & -0.8 & -40.8 & 191 & 4 & -157 \\
Organic mulching & 0.5 & 11.9 & 323 & 12 & 146 \\
Drip and synthetic mulching & 6.2 & 174.8 & 429 & 15 & 2660 \\
\hline
\end{tabular}

Table G6. Marginal cost and WF reduction per subsequent measure in the MCC for WF reduction in potato production for the baseline of sprinkler irrigation combined with full irrigation and no mulching.

\begin{tabular}{lrr|rrr}
\hline \multirow{2}{*}{ Measures } & \multicolumn{2}{c|}{ Marginal cost } & \multicolumn{2}{c}{ WF reduction } & \multirow{2}{*}{ Total cost USD ha $^{-1}$} \\
\cline { 2 - 5 } & USD ha $^{-1} \mathrm{per} \mathrm{m}^{3} \mathrm{ha}^{-1}$ & $\mathrm{USD} \mathrm{ha}^{-1} \mathrm{per} \mathrm{m}^{3} \mathrm{t}^{-1}$ & $\mathrm{~m}^{3} \mathrm{ha}^{-1}$ & $\mathrm{~m}^{3} \mathrm{t}^{-1}$ & \\
\hline Deficit irrigation & -0.7 & -33.1 & 228 & 5 & -157 \\
Organic mulching & 0.4 & 9.6 & 403 & 15 & 147 \\
Drip and synthetic mulching & 3.5 & 101.6 & 458 & 16 & 1623 \\
\hline
\end{tabular}


Competing interests. The authors declare that they have no conflict of interest.

Acknowledgements. This research was conducted as part of FIGARO, a project funded by the European Commission as part of the Seventh Framework Programme. The authors thank all the consortium partners in the project. The present work was developed within the framework of the Panta Rhei Research Initiative of the International Association of Hydrological Sciences (IAHS).

Edited by: Nunzio Romano

Reviewed by: four anonymous referees

\section{References}

Addams, L., Boccaletti, G., Kerlin, M., and Stuchtey, M.: Charting our water future: economic frameworks to inform decisionmaking, McKinsey \& Company, New York, 2009.

Afshar, A. and Neshat, A.: Evaluation of Aqua Crop computer model in the potato under irrigation management of continuity plan of Jiroft region, Kerman, Iran, International journal of Advanced Biological and Biomedical Research, 1, 1669-1678, 2013.

Agri-Info.Eu: On-line database, Wages and Labour Costs in European Agriculture, available at: http://www.agri-info.eu/english/ tt_wages.php, last access: June 2016.

Ali, M. H.: Water Application Methods, in: Practices of Irrigation \& On-farm Water Management, Springer, New York, USA, 35-63, 2011.

Allen, R., Pereira, L., Raes, D., and Smith, M.: Crop evapotranspiration. FAO irrigation and drainage paper 56, FAO, Rome, Italy, 10, 1998.

Baldock, D., Dwyer, J., Sumpsi, J., Varela-Ortega, C., Caraveli, H., Einschütz, S., and Petersen, J.: The environmental impacts of irrigation in the European Union, Institute for European Environmental Policy, London, 2000.

Bockel, L., Sutter, P., Touchemoulin, O., and Jönsson, M.: Using marginal abatement cost curves to realize the economic appraisal of climate smart agriculture policy options, Methodology, Food and Agriculture Organization (FAO), Rome, Italy, 3, 2012.

Brouwer, C., Prins, K., and Heibloem, M.: Irrigation water management: irrigation scheduling, Training manual, Food and Agriculture Organization (FAO), Rome, Italy, 4, 1989.

Chukalla, A. D., Krol, M. S., and Hoekstra, A. Y.: Green and blue water footprint reduction in irrigated agriculture: effect of irrigation techniques, irrigation strategies and mulching, Hydrol. Earth Syst. Sci., 19, 4877-4891, https://doi.org/10.5194/hess-19-48772015, 2015.

Custodio, E. and Gurguí, A.: Groundwater economics, Elsevier, 1989.

English, M.: Deficit irrigation. I: Analytical framework, J. Irrig. Drain. E.-ASCE, 116, 399-412, 1990.

Enkvist, P., Nauclér, T., and Rosander, J.: A cost curve for greenhouse gas reduction, McKinsey Quarterly, New York, USA, 1, 34, 2007.

Ercin, A. E. and Hoekstra, A. Y.: Water footprint scenarios for 2050: A global analysis, Environ. Int., 64, 71-82, 2014.
Eurostat: Half-yearly electricity and gas prices, second half of year, 2012-14 (EUR per kWh) YB15, available at: http://ec.europa.eu/ eurostat/statistics-explained, last access: June 2016.

FAO: Annex I Crop parameters, AquaCrop reference manual, Food and Agriculture Organization of the United Nations, Rome, Italy, 2012.

FAO: AQUASTAT on-line database, Food and Agricultural Organization, Rome, Italy, available at: http://www.fao.org, last access: November 2016.

FAOSTAT: On-line database, Food and Agricultrural Organisation price statistics, 2015, available at: https://knoema.com/ FAOPS2015July/fao-price-statistics-2015, last access: April 2017.

Fereres, E. and Soriano, M. A.: Deficit irrigation for reducing agricultural water use, J. Exp. Bot., 58, 147-159, 2007.

Fischer, G., Tubiello, F. N., Van Velthuizen, H., and Wiberg, D. A.: Climate change impacts on irrigation water requirements: effects of mitigation, 1990-2080, Technol. Forecast. Soc., 74, 10831107, 2007.

Garrido, A. and Calatrava, J.: Agricultural water pricing: EU and Mexico, Consultant report for the OECD, Document, 2010.

Gómez-Limón, J. A. and Riesgo, L.: Irrigation water pricing: differential impacts on irrigated farms, Agr. Econ., 31, 47-66, 2004.

Gonzalez-Alvarez, Y., Keeler, A. G., and Mullen, J. D.: Farm-level irrigation and the marginal cost of water use: Evidence from Georgia, J. Environ. Manage., 80, 311-317, 2006.

Hannam, J. A., Hollis, J. M., Jones, R. J. A., Bellamy, P. H., Hayes, S. E., Holden, A., Liedekerke, M. H., and Montanarella, L.: SPE-2: The soil profile analytical database for Europe, Beta Version 2.0, http://esdac.jrc.ec.europa.eu/content/ european-soil-database-v20-vector-and-attribute-data (last access: 16 June 2014), 2009.

Hoekstra, A. Y.: Sustainable, efficient, and equitable water use: the three pillars under wise freshwater allocation, Wiley Interdisciplinary Reviews: Water, 1, 31-40, 2014.

Hoekstra, A. Y.: Water Footprint Assessment: Evolvement of a New Research Field, Water Resour. Manage., 31, 3061-3081, 2017.

Hoekstra, A. Y., Chapagain, A. K., Aldaya, M. M., and Mekonnen, M. M.: The Water Footprint Assessment Manual: Setting the Global Standard, Earthscan, London, UK, 2011.

Jensen, M. H. and Malter, A. J.: Protected agriculture: a global review, World Bank, Washington, DC, USA, 1995.

Kay, M. and Hatcho, N.: Small-scale Pumped Irrigation: Energy and Cost: irrigation Water Management Training Manual, Food and Agriculture Organization (FAO), Rome, Italy, 1992.

Kesicki, F.: Marginal abatement cost curves for policy makingexpert-based vs. model-derived curves, Energy Institute, University College London, 2010.

Kesicki, F. and Ekins, P.: Marginal abatement cost curves: a call for caution, Clim. Policy, 12, 219-236, https://doi.org/10.1080/14693062.2011.582347, 2012.

Kesicki, F. and Strachan, N.: Marginal abatement cost (MAC) curves: confronting theory and practice, Environ. Sci. Policy, 14, 1195-1204, https://doi.org/10.1016/j.envsci.2011.08.004, 2011.

Khan, S., Khan, M., Hanjra, M., and Mu, J.: Pathways to reduce the environmental footprints of water and energy inputs in food production, Food Policy, 34, 141-149, 2009.

Klein Tank, A., Wijngaard, J., Können, G., Böhm, R., Demarée, G., Gocheva, A., Mileta, M., Pashiardis, S., Hejkrlik, L., and Kern- 
Hansen, C.: Daily dataset of 20th-century surface air temperature and precipitation series for the European Climate Assessment, Int. J. Climatol., 22, 1441-1453, 2002.

Klonsky, K.: Comparison of production costs and resource use for organic and conventional production systems, Am. J. Agr. Econ., 94, 314-321, 2012.

Lallana, C. and Marcuello, C.: Indicator fact sheet (WQ2): Water use by sectors. European Environment Agency, Copenhagen, available at: http://www.eea.europa.eu, last acess: June 2016.

Lamont, W. J.: Plastics: Modifying the microclimate for the production of vegetable crops, HortTechnology, 15, 477-481, 2005.

Lamont, W. J., Hensley, D. L., Wiest, S., and Gaussoin, R. E.: Relay-intercropping muskmelons with Scotch pine Christmas trees using plastic mulch and drip irrigation, Hortscience, 28, 177-178, 1993.

Lewis, A. and Gomer, S.: An Australian cost curve for greenhouse gas reduction, Report, McKinsey and Company, Australia, 2008.

MacLeod, M., Moran, D., Eory, V., Rees, R., Barnes, A., Topp, C. F., Ball, B., Hoad, S., Wall, E., and McVittie, A.: Developing greenhouse gas marginal abatement cost curves for agricultural emissions from crops and soils in the UK, Agr. Syst., 103, 198209, 2010.

Mateo-Sagasta, J., Ongley, E., Hao, W., and Mei, X.: Guidelines to Control Water Pollution from Agriculture in China: Decoupling water pollution from agricultural production, Food and Agricultural Organization, Rome, Italy, 2013.

McCraw, D. and Motes, J. E.: Use of plastic mulch and row covers in vegetable production, Cooperative Extension Service. Oklahoma State University, USA, OSU Extension Facts F-6034, 1991.

Mekonnen, M. M. and Hoekstra, A. Y.: Water footprint benchmarks for crop production: A first global assessment, Ecol. Indic., 46, 214-223, 2014.

Mekonnen, M. M. and Hoekstra, A. Y.: Four billion people facing severe water scarcity, Science Advances, 2, e1500323, https://doi.org/10.1126/sciadv.1500323, 2016.

Molden, D., Oweis, T., Steduto, P., Bindraban, P., Hanjra, M. A., and Kijne, J.: Improving agricultural water productivity: between optimism and caution, Agr. Water Manage., 97, 528-535, 2010.

Mulumba, L. N. and Lal, R.: Mulching effects on selected soil physical properties, Soil Till. Res., 98, 106-111, 2008.

Oosthuizen, L. K., Botha, P. W., Grove, B., and Meiring, J. A.: Costestimating procedures for drip-, micro- and furrow-irrigation systems, Water SA, 31, 403-406, 2005.

Phocaides, A.: Technical handbook on pressurized irrigation techniques, Food and Agric. Organ., Rome, 2000.

Raes, D.: The ETo Calculator. Reference Manual Version 3.2, Food and Agriculture Organization of the United Nations, Rome, Italy, 2012.

Raes, D., Steduto, P., C. Hsiao, T., and Fereres, E.: Reference Manual AquaCrop plug-in program, Food and Agriculture Organization of the United Nations, Land and Water Division, Rome, Italy, 2011.

Raes, D., Steduto, P., Hsiao, T. C., and Fereres, E.: Chapter 3 AquaCrop, Version 4.0, Food and Agriculture Organization of the United Nations, Land and Water Division, Rome, Italy, 2012.

Raes, D., Steduto, P., and Hsiao, C. T.: Reference manual, Chapter 2, AquaCrop model, Version 4.0, Food and Agriculture Organization of the United Nations, Rome, Italy, 2013.
Reich, D. A., Broner, I., Chavez, J., and Godin, R. E.: Subsurface Drip Irrigation, Colorado State University Extension, Denver, USA, 2009.

Ritchie, J.: Model for predicting evaporation from a row crop with incomplete cover, Water Resour. Res., 8, 1204-1213, 1972.

Rosegrant, M. W., Cai, X., and Cline, S. A.: World water and food to 2025: dealing with scarcity, Intl. Food Policy Res. Inst., Washington DC, USA, 2002.

Saad, A. M., Mohamed, M. G., and El-Sanat, G. A.: Evaluating AquaCrop model to improve crop water productivity at North Delta soils, Egypt, Adv. Appl. Sci. Res., 5, 293-304, 2014.

Samarawickrema, A. and Kulshreshtha, S.: Marginal value of irrigation water use in the South Saskatchewan River Basin, Canada, Great Plains Research, 19, 73-88, 2009.

Saxton, K., Rawls, W. J., Romberger, J., and Papendick, R.: Estimating generalized soil-water characteristics from texture, Soil Sci. Soc. Am. J., 50, 1031-1036, 1986.

Shaxson, F. and Barber, R.: Optimizing soil moisture for plant production. The significance of soil porosity, Food and Agriculture Organization of the United Nations, Rome, Italy, 2003.

Shrefler, J. and Brandenberger, L.: Use of plastic mulch and row covers in vegetable production, Oklahoma State University: Oklahoma Cooperative Extension Service, 2014.

Steduto, P., Hsiao, T. C., Raes, D., and Fereres, E.: AquaCrop-The FAO Crop Model to Simulate Yield Response to Water: I. Concepts and Underlying Principles, Agron. J., 101, 426-437, 2009a.

Steduto, P., Raes, D., Hsiao, T., Fereres, E., Heng, L., Howell, T., Evett, S., Rojas-Lara, B., Farahani, H., Izzi, G., Oweis, T., Wani, S., Hoogeveen, J., and Geerts, S.: Concepts and Applications of AquaCrop: The FAO Crop Water Productivity Model, in: Crop Modeling and Decision Support, edited by: Cao, W., White, J., and Wang, E., Springer, Berlin, Germany, 175-191, $2009 \mathrm{~b}$.

Steduto, P., Hsiao, T. C., Raes, D., and Fereres, E.: Crop yield response to water, Food and Agriculture Organization of the United Nations Italy, Rome, 2012.

Tata-Group: Tata Industrial Water Footprint Assessment: Results and Learning, http://waterfootprint.org/media/downloads/WFN_ 2013.Tata_Industrial_Water_Footprint_Assessment.pdf (last access: 10 June 2016), 2013.

Vörösmarty, C. J., Green, P., Salisbury, J., and Lammers, R. B.: Global water resources: vulnerability from climate change and population growth, Science, 289, 284-288, 2000.

Williams, J. R. and Izaurralde, R. C.: The APEX model, Watershed models, 437-482, 2006.

Zhuo, L., Mekonnen, M. M., and Hoekstra, A. Y.: Benchmark levels for the consumptive water footprint of crop production for different environmental conditions: a case study for winter wheat in China, Hydrol. Earth Syst. Sci., 20, 4547-4559, https://doi.org/10.5194/hess-20-4547-2016, 2016.

Zou, X., Li, Y. E., Cremades, R., Gao, Q., Wan, Y., and Qin, X.: Cost-effectiveness analysis of water-saving irrigation technologies based on climate change response: A case study of China, Agr. Water Manage., 129, 9-20, 2013.

Zwart, S. J., Bastiaanssen, W. G., de Fraiture, C., and Molden, D. J.: A global benchmark map of water productivity for rainfed and irrigated wheat, Agr. Water Manage., 97, 1617-1627, 2010. 